\title{
Improving adhesion between luting cement and zirconia-based ceramic with an alternative surface treatment
}

Aurealice Rosa Maria MARTINS ${ }^{(a)}$ Valéria Bisinoto GOTTI(a) Marcos Massao SHIMANO (b) Gilberto Antônio BORGES(c) Luciano de Souza GONÇALVES(c)

(a) Universidade Estadual de Campinas UNICAMP, Piracicaba Dental School, Department of Restorative Dentistry, Piracicaba, SP, Brazil.

(b) Universidade Federal do Triângulo Mineiro - UFTM, School of Engeneering, Department of Mechanical Engineering, Uberaba, MG, Brazil.

(c) Universidade de Uberaba - UNIUBE, School of Dentistry, Biomaterials Division, Uberaba, MG, Brazil.

Declaration of Interests: The authors certify that they have no commercial or associative interest that represents a conflict of interest in connection with the manuscript.

Corresponding Author:

Luciano de Souza Gonçalves

E-mail: goncalves1976@yahoo.com.br

DOI: 10.1590/1807-3107BOR-2015.vol29.0054

Submitted: Aug 07, 2014

Accepted for publication: Jan 08, 2015

Last revision: Feb 20, 2015

\begin{abstract}
This study evaluated the influence of an alternative surface treatment on the microshear bond strength ( $\mu \mathrm{sbs})$ of zirconia-based ceramic. Thirty-five zirconia disks were assigned to five groups according to the following treatments: Control (CO), glass and silane were not applied to the zirconia surface; G1, air blasted with $100 \mu \mathrm{m}$ glass beads + glaze + silane; G2, a gel containing 15\% (by weight) glass beads applied to the ceramic surface + glaze + silane; G3, a gel containing $25 \%$ (by weight) glass beads applied to the ceramic surface + glaze + silane; and G4, a gel containing 50\% (by weight) glass beads applied to the ceramic surface + glaze + silane. The specimens were built up using RelyX $\mathrm{ARC}^{\circledR}$, according to the manufacturer's recommendations, and inserted in an elastomeric mold with an inner diameter of $0.8 \mathrm{~mm}$. The $\mu$ sbs test was performed using a testing machine at a crosshead speed of $0.5 \mathrm{~mm} / \mathrm{min}$. ANOVA and Tukey's test $(\mathrm{p}<0.05)$ were applied to the bond strength values (in MPa). CO (15.6 \pm 4.1$)$ showed the lowest $\mu$ sbs value. There were no statistical differences between the G1 (24.9 \pm 7.4$)$, G2 (24.9 \pm 2.3$), G 3(35.0 \pm 10.3)$ and G4 (35.3 \pm 6.0$)$ experimental groups. Those groups submitted to surface treatments with higher concentrations of glass showed a lower frequency of adhesive failures. In conclusion, the glass application improved the interaction between the ceramic and the luting cement.
\end{abstract}

Keywords: Zirconium; Resin Cements; Cementation; Dental Materials.

\section{Introduction}

Zirconia-based ceramics $\left(\mathrm{ZrO}_{2}\right)$ have important properties, such as chemical durability, high fracture toughness, elastic modulus and hardness, influenced by the tetragonal-to-monoclinic phase transformation. ${ }^{1,2,3}$ Despite the difficulty to bond the surface of $\mathrm{ZrO}_{2}$, resin cements are a good option to bond indirect restorative materials to dental tissues, ${ }^{4}$ including $\mathrm{ZrO}_{2}$. This is especially the case when a surface treatment is used, ${ }^{5}$ because this ceramic is composed of a glass-free polycrystalline microstructure. Therefore, hydrofluoric etching and silanization do not improve the bond strength between resin and high crystalline content ceramics. ${ }^{6,7,89}$ For this reason, a different mode of treatment is necessary to provide adequate bond strength.

In vitreous ceramics, hydrofluoric acid etching can be used to modify the surface. Hydrofluoric acid selectively removes the glassy matrix, 
creating a porous surface. ${ }^{10,11}$ After conducting the surface treatment, a silane-coupling agent is applied to the ceramic surface. Silane is a bi-functional molecule capable of forming a siloxane network with the hydroxyl $(\mathrm{OH})$ of the silica on the ceramic surface, and co-polymerize with the resinous matrix of composites. However, this chemical reaction is not applicable to zirconia-based ceramics, because they lack a silica phase., ${ }^{9,12,13,14,15}$ Some manufacturers recommend a tribochemical silica coating as an alternative treatment in an attempt to improve the bond between $\mathrm{ZrO}_{2}$ and resin cements. ${ }^{16,17}$ The silica embedded on the ceramic surface is able to react by silane coupling, and should be more effective than conventional air abrasion..$^{18,19}$ This abrasion technique only increases the surface roughness of the zirconia ${ }_{1}{ }^{20}$ increasing the bonding surface area, and removes any contaminants from the ceramic surface. ${ }^{21}$ Notwithstanding, controversy exists regarding the efficacy any of these treatments. . $^{16,22,23,24}$

Air blasting with glass beads is another attempt to modify the zirconia surface and increase the bond strength between zirconia-based ceramics and resin cement. Previous studies have indicated that the fusion of glass beads on a zirconia surface can increase the bond strength to composite resin cements, as compared with untreated surfaces. ${ }^{13,25}$ However, in these studies, the fused glass was removed by selective infiltration etching (SIE), creating mechanical retentions. On the other hand, the presence of the glass beads fused on the $\mathrm{ZrO}_{2}$ could establish a chemical bond with the cement through the silane, in addition to modifying the surface topography. For this reason, the development of a simple, effective and inexpensive technique for applying glass beads on $\mathrm{ZrO}_{2}$ becomes necessary.

The aim of this study was to evaluate: i) if the bond strength between $\mathrm{ZrO}_{2}$ and resin cement could be increased by fusing glass beads, using two application techniques; ii) if the failure mode could be influenced by the quantity of glass on the ceramic surface.

\section{Methodology}

Thirty-five zirconia discs (Cercon, DeguDent $\mathrm{GmbH}$, Hanau, Germany) were cut into sections with a water-cooled low-speed diamond saw (Isomet 1000, Buehler, Lake Buff, USA) from pre-sintered Y-TZP blocks. After completing the full sintering process, the discs (20 $\mathrm{mm}$ in diameter and $2 \mathrm{~mm}$ in thickness) were wet polished with \#600 and \#1200 silicon carbide paper (Norton S.A., São Paulo, Brazil). The zirconia surfaces were air-abraded with $50 \mu \mathrm{m}$ aluminum trioxide $\left(\mathrm{Al}_{2} \mathrm{O}_{3}\right)$ particles at a pressure of 4 bar, from a distance of $10 \mathrm{~mm}$ for $10 \mathrm{~s}$. After air abrasion, the zirconia discs were cleaned for $5 \mathrm{~min}$ in an ultrasonic ethanol bath and $5 \mathrm{~min}$ in distilled water (Ultrasonic Cleaner - Odontobras Ind. \& Com. de Equipamentos Médico Odontológicos Ltda., Ribeirão Preto, Brazil), and then dried with oil-free air. The zirconia discs were randomly separated into five groups $(\mathrm{n}=7)$ : Control (CO) - no treatment; G1 - air blasted with Rolloblast ${ }^{\circledR}$ $100 \mu \mathrm{m}$ glass beads (Renfert $\mathrm{GmbH}$, Hilzigen, Germany), using an air-blasting device (Microetch, Bio-Art Equipamentos Odontológicos Ltda., São Carlos, Brazil), at a distance of $10 \mathrm{~mm}$, perpendicular to the disc surface for $20 \mathrm{~s}+$ baking in a Titan $98^{\circledR}$ ceramic oven (EDG Equipamentos e Controles Ltda., São Carlos, Brazil), at a preheated temperature of $400^{\circ} \mathrm{C}$ for $4 \mathrm{~min}$, with a heating rate of $55^{\circ} \mathrm{C} / \mathrm{min}$ up to $900^{\circ} \mathrm{C}$, and maintaining this temperature for 6 min; G2, G3 and G4, in which a water-based gel containing $15 \%, 25 \%$ or $50 \%$ by weight (respectively) glass beads was applied to the ceramic surface with a brush used for application of ceramic primers in a single direction for 20s. After applying the gel, the zirconia discs were baked using the same process as that used for G1. This baking procedure was adopted to melt the glass beads onto the ceramic surface. The parameters used were set as a standard program that was entered in the furnace memory.

Polyvinyl siloxane molds (Vigodent Coltene S.A. Indústria e Comércio, Rio de Janeiro, Brazil), $0.5 \mathrm{~mm}$ thick, were constructed with five cylinder-shaped orifices ( $0.8 \mathrm{~mm}$ in diameter) and were placed on the ceramic disc surface to delimit the adhesion area. Before positioning the mold, the silane agent was applied to the surface of G1, G2, G3 and G4. The adhesion was performed by one operator, under controlled conditions of temperature and humidity $\left(23 \pm 2{ }^{\circ} \mathrm{C}\right.$ and $50 \pm 5 \%$ ). RelyX ARC resin cement (3M ESPE, St. Paul, USA) was prepared according to the manufacturer's instructions and inserted into the orifice of the mold, with a \#5 explorer 
(Duflex - SS White do Brasil, Rio de Janeiro, Brazil). Excess cement was removed using a \#24 spatula (Duflex). The orifices were filled with the resin luting cements, and a transparent polyester strip was placed over the filled orifices. A constant and uniform load of $454 \mathrm{gF}$ (1 pound F) was applied for $1 \mathrm{~min}$, using a custom-made device. The resin cement was photo activated for $20 \mathrm{~s}$ for each orifice, using a continuous mode with a LED Radii Cal (SDI. Victoria ${ }^{\circledR}$, Australia) and an irradiance of $1,400 \mathrm{~mW} / \mathrm{cm}^{2}$, as verified with a power meter (Ophir Optronics Ltd. ${ }^{\circledR}$, Jerusalem, Israel). After the samples were activated, they were stored for $24 \mathrm{~h}$ at $37^{\circ} \mathrm{C}, 100 \%$ relative humidity, and protected from light.

Microshear bond strength ( $\mu \mathrm{sbs})$ testing was performed in a testing machine (EMIC DL $3000^{\circledR}$-EMIC - Equipamentos e Sistemas de Ensaios Ltda., São José dos Pinhais, Brazil), using a chisel with a $0.5 \mathrm{~mm} / \mathrm{min}$ crosshead speed until failure. The average of the five repetitions on the specimens was calculated to obtain the mean value of the bond strength of each zirconia disc. The mean of the 7 discs of each group was submitted to one-way ANOVA, and multiple comparisons were performed using Tukey's post-hoc test. Differences were considered significant at $p<0.05$. Figure 1 shows a schematic of the experimental procedures. The failure mode analysis was observed under scanning electron microscopy (SEM) (JSM-5600LV, Jeol Ltd., Tokyo, Japan) at $15 \mathrm{Kv}$ and at $80 \mathrm{x}$ magnification, and classified as cohesive $(\mathrm{COH})$ - within the cement layer, adhesive (ADH), or mixed (MIX) - involving cement and ceramic substrates.

Three additional specimens were made for each surface treatment, to evaluate the modifications on the surface morphology, as described above for G1 to G4. The zirconia discs were coated with carbon and examined with a back-scattering electron detector on SEM (Jeol Ltd., Tokyo, Japan), to distinguish the number of glass and zirconia phases.
(A)

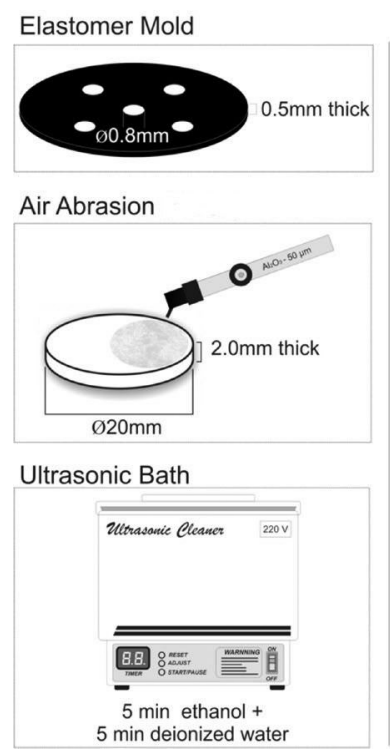

(B)

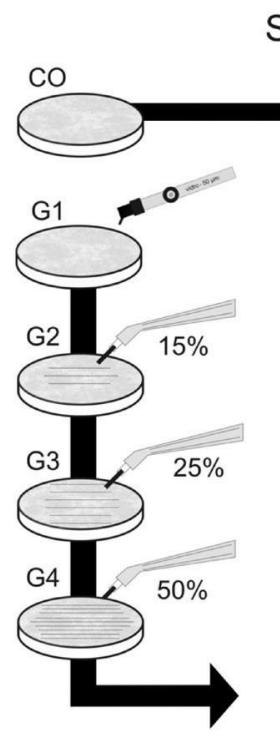

Specimens Preparation

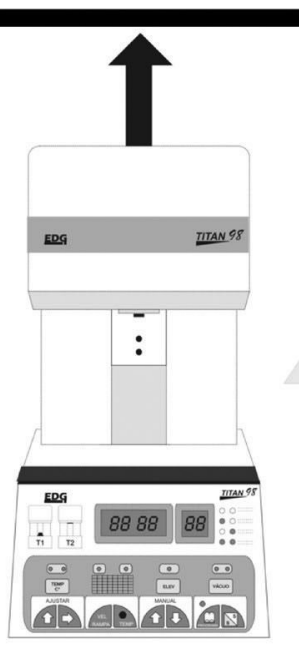

(C)

Microshear Bond Strength
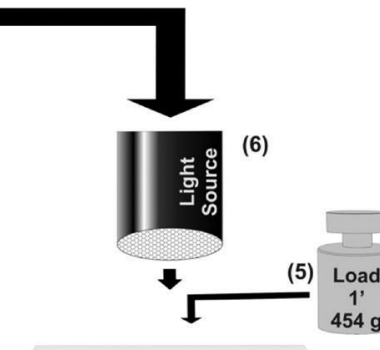

(4)
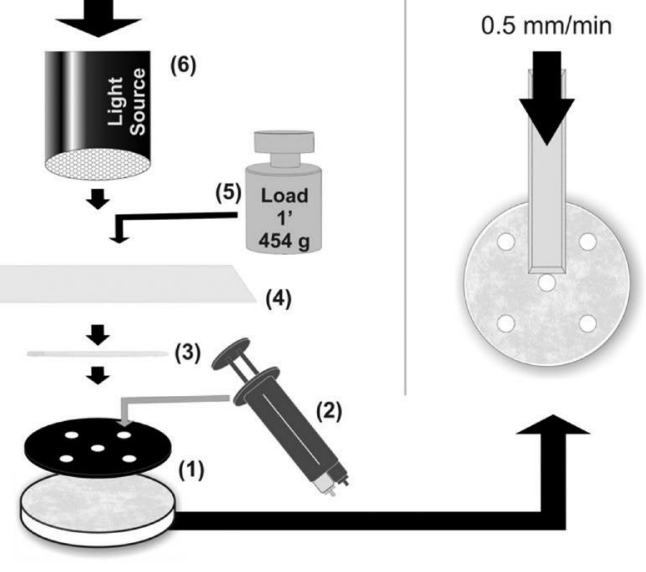

Figure 1. Image $A$ shows the elastomeric mold, abrasion with $\mathrm{Al}_{2} \mathrm{O}_{3}$ particles and ultrasonic bath prior to adhesive procedures. Image $\mathrm{B}$ shows the treatments applied to each group, the $\mathrm{CO}$ (non-treated) and glass applications, according to each group, as well as the firing (G1-G4). Observe the following adhesion procedures: (1) an elastomer mold positioned onto the zirconia disc surface after silane coating, in the groups treated with glass; (2) orifices filled with resin cement; (3) polyester strip and (4) glass slab over the filled mold; (5) cementation load applied for $1 \mathrm{~min}(454 \mathrm{gF})$; (6) photo-activation of resin cement (20 s in each orifice). Image $C$ represents the $\mu$ sbs testing. 


\section{Results}

The results of $\mu \mathrm{sbs}$ and distribution of the failure modes in each group are shown in Table 1. CO presented significantly lower bond strength values, as compared with all the other groups $(p=0.0098)$. No significant differences were found when the glass was applied on the zirconia surfaces, regardless of the type or quantity of glass applied $(\mathrm{p} \leq 0.08)$. The failure analysis performed on SEM, with a secondary electron detector, showed that the $\mathrm{ADH}$ mode was the predominant failure mode for $\mathrm{CO}$, and a decrease in the frequency of this failure mode was observed according to increasing amounts of glass on the zirconia surface. In contrast, a predominance of the MIX failure mode was detected for G2 to G4. A detail of a MIX failure, with adhered resin cement on a glass bead and the surface of the zirconia, is shown in Figure 2. The $\mathrm{COH}$ mode (Figure 3 ) was observed in G3 and G4. Backscattering images show the increase in the amount of fused glass on the surface of $\mathrm{ZrO}_{2}$ for G2, G3 and G4 (Figures 4A, 4B and 4C).

\section{Discussion}

The bond strength between the resin cement and $\mathrm{ZrO}_{2}$ has been extensively studied. Methods such as air-abrasion, tribochemical silica coating associated to silane-coupling, the use of ceramic-primers and, more recently, SIE, have been used in order to improve the adhesion to $\mathrm{ZrO}_{2}$. However, whereas some of these treatments have shown good results, ${ }^{4,6,8,26}$ other methods have not proven their effectiveness completely. ${ }^{7,9,20,21,27}$

In the present study, the application of glass to the $\mathrm{ZrO}_{2}$ surfaces improved the bond strength between the ceramic and resin cement, regardless of the technique (air blast or gel) or concentration of the gel $(15,25$ or $50 \%$ of glass by weight). The increase in the bond strength probably occurred due to addition of silica to the surface of the substrate. After the application and fusion of glass on the zirconia disc surface, a silane-coupling was applied, resulting in stable chemical bonds between the hydroxyl groups $(\mathrm{OH})$ of the silica on the glass surface and the resin cement, ${ }^{12,15}$ corroborating previous studies. ${ }^{6,7,25}$ Therefore, the lower $\mu$ sbs observed by the $\mathrm{CO}$ can be explained by the low

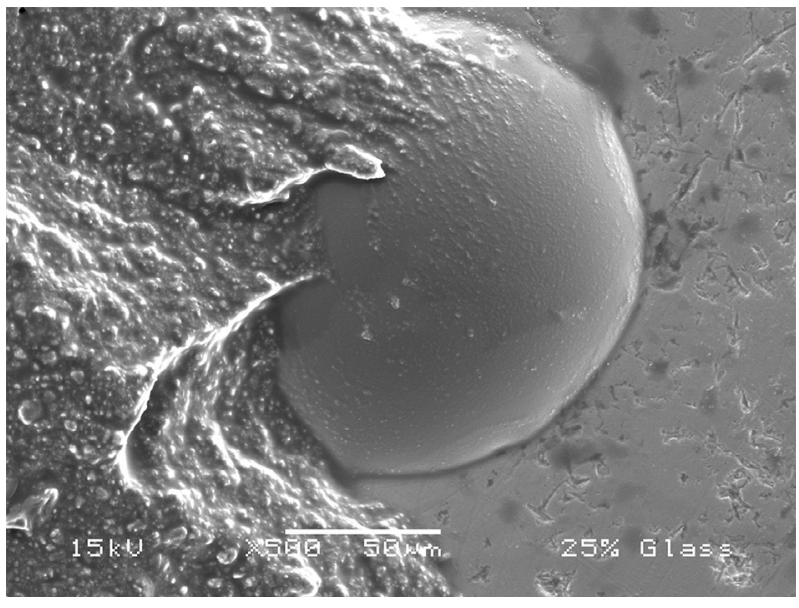

Figure 2. Resin cement adhered to the glass bead on the zirconia surface.

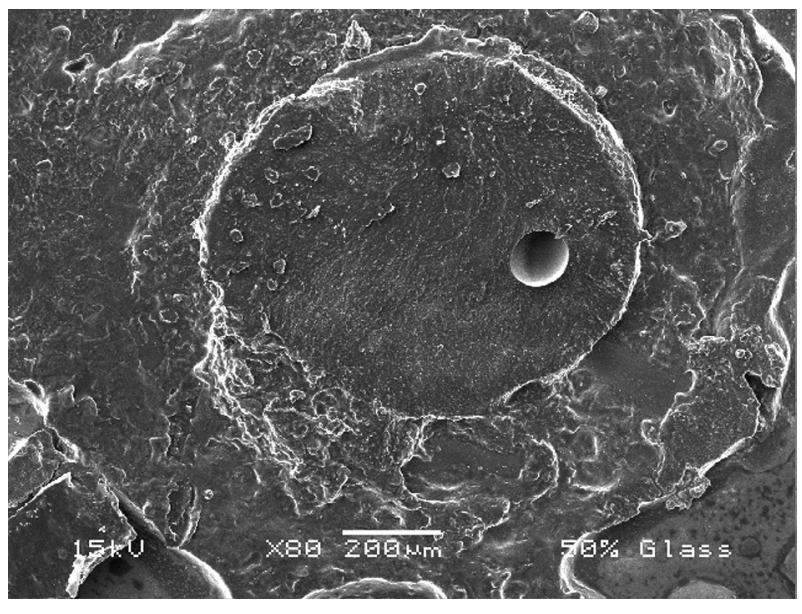

Figure 3. $\mathrm{COH}$ mode with an air bubble within the cement bulk.

Table 1. Means (standard deviations) for $\mu$ sbs and SEM classification of the following failure modes: $\mathrm{ADH}$ - adhesive; MIX - mixed, involving luting material and ceramic; $\mathrm{COH}$ - cohesive, within the luting material.

\begin{tabular}{lcccc}
\hline \multirow{2}{*}{ Groups } & \multirow{2}{*}{$\begin{array}{c}\mu \text { sbs } \\
(\mathrm{MPa})\end{array}$} & \multicolumn{3}{c}{ Failure mode (\%) } \\
\cline { 3 - 5 } & ADH & MIX & $\mathrm{COH}$ \\
\hline Control & $15.57(4.1) \mathrm{B}$ & 90 & 10 & - \\
G1 & $24.86(7.4) \mathrm{A}$ & 80 & 20 & - \\
Air blast & $24.95(2.3) \mathrm{A}$ & 40 & 60 & - \\
G2 & & & & \\
Gel 15\% & $35.05(10.3) \mathrm{A}$ & 30 & 50 & 20 \\
G3 & & & & \\
Gel 25\% & $35.52(6.0) \mathrm{A}$ & 5 & 65 & 30 \\
G4 & & & & \\
Gel 50\% & &
\end{tabular}

Different letters in the first column indicate statistically differences (Tukey's test, $p<0.05$ ). 

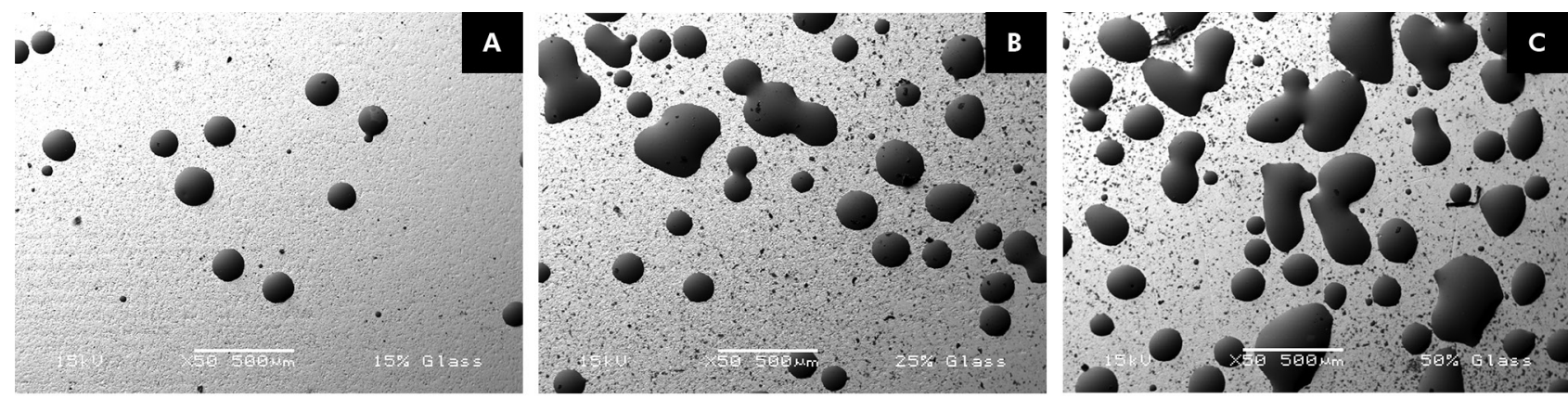

Figure 4. The increase in the amount of glass on the zirconia surface for $G 2, G 3$ and $G 4$ can be seen respectively in images $A, B$ and $C$ (back-scattering electron detector). Individual fused glass beads are shown in Image A, and groups of beads fused together can be seen in images $B$ and $C$.

micromechanical interlocking between the resin cement and zirconia surface. In addition, the absence of glass (silica) on the ceramic surface did not establish a siloxane network between the silane coupling and the ceramic surface. The quantity of glass on the zirconia surface had no influence on the bond strength among the experimental groups (Table 1). However, an evident modification in the failure mode was observed.

Table 1 shows the high percentage of $\mathrm{ADH}$ failure mode that occurred for the CO and G1 groups. According to a previous study, adhesive failures are usually associated with lower bond strength values. ${ }^{28}$ Notwithstanding, the type of adhesion (mechanical interlocking or chemical bonds) also appears to have an influence on the failure mode. Although the bond strength values among the experimental groups (G1 to G4) were similar, the G1 failure mode was predominantly ADH. This probably occurred because G1 was not baked; therefore, the glass was not fused onto the $\mathrm{ZrO}_{2}$ surface, as occurred with the glass beads. A previous study reports that the silica content on the silica-coated surface is about $11 \%$, and these particles do not appear to have become embedded on the zirconia surface. ${ }^{29}$ Therefore, the G1 failure mode may have been influenced, leading to the similar bond strengths, in comparison with the other experimental groups. In addition, the limitations of the $\mu$ sbs test, such as non-uniform stress distribution, must be considered, because this distribution may influence the failure mode. ${ }^{30}$
The modification of the failure mode may have contributed to the similar bond strength values among the experimental groups. ${ }^{6}$ The fused glass was strongly bonded to the zirconia surface, resulting in an effective adhesion. The silane coupling promoted a chemical bond between the glass and the resin cement, increasing the bond strength and directing the stress into the resin cement layer. The interaction among the resin cement, glass-beads and zirconia surface can be seen in Figure 2. The stress may have been concentrated in areas that were poorly polymerized or that contained air bubbles within the cement (as shown in Figure 3), increasing the occurrence of MIX failures and decreasing the percentage of $\mathrm{ADH}$ failures. Groups containing a higher amount of glass on the ceramic surface presented failures that involved a larger number of resin cements, especially in G3 and G4, where $\mathrm{COH}$ failures occurred. In Figure 4, images $A, B$ and $C$ show the differences in surface morphology of the G2, G3 and G4 groups, respectively. The SEM images obtained with the back-scattering electron detector show the zirconia surface as a white phase, whereas the dark, raised bubbles are the particles of glass fused to the ceramic surface. The increase in the amount of glass on the zirconia surface, according to the concentration of gel used in each specimen, is apparent, resulting in increased irregularities of the surface and a large presence of silica (which can react with the silane coupling), developing points of stress concentration within the cement layer.

Even though the increase in $\mu$ sbs and the modification in failure modes were verified through 
this study, more studies are necessary to evaluate the effect of storage, mechanical stress, and water degradation combined with different resin cements, insofar as surface characteristics may be key determinants of their bonding potential with zirconia ceramics. ${ }^{21}$ In addition, data regarding marginal and internal fit are important for assessing the clinical applicability of this alternative surface treatment.

\section{References}

1. Christel P, Meunier A, Heller M, Torre JP, Peille CN. Mechanical properties and short-term in-vivo evaluation of yttrium-oxide-partially-stabilized zirconia. J Biomed Mater Res. 1989 Jan;23(1):45-61.

2. Piconi C, Maccauro G. Zirconia as a ceramic biomaterial. Biomaterials. 1999 Jan;20(1):1-25.

3. Guazzato M, Albakry M, Ringer SP, Swain MV. Strength, fracture toughness and microstructure of a selection of all-ceramic materials. Part II. Zirconia-based dental ceramics. Dent Mater. 2004 Jun;20(5):449-56.

4. Attia A. Bond strength of three luting agents to zirconia ceramic - influence of surface treatment and thermocycling. J Appl Oral Sci. 2011 Aug;19(4):388-95.

5. Kern M. Bonding to oxide ceramics-Laboratory testing versus clinical outcome. Dent Mater. 2015 Jan;31(1):8-14.

6. Aboushelib MN, Feilzer AJ, Kleverlaan CJ. Bonding to zirconia using a new surface treatment. J Prosthodont. 2010 Jul;19(5):340-6.

7. Souza GM, Silva NR, Paulillo LA, Goes MF, Rekow ED, Thompson VP. Bond strength to high-crystalline content zirconia after different surface treatments. J Biomed Mater Res B Appl Biomater. 2010 May;93(2):318-23.

8. Della Bona A, Borba M, Benetti P, Cecchetti D. Effect of surface treatments on the bond strength of a zirconia-reinforced ceramic to composite resin. Braz Oral Res. 2007 Jan-Mar;21(1):10-5.

9. Qeblawi DM, Munoz CA, Brewer JD, Monaco EA, Jr. The effect of zirconia surface treatment on flexural strength and shear bond strength to a resin cement. J Prosthet Dent. 2010 Apr;103(4):210-20.

10. Oyague RC, Monticelli F, Toledano M, Osorio E, Ferrari $\mathrm{M}$, Osorio R. Effect of water aging on microtensile bond strength of dual-cured resin cements to pre-treated sintered zirconium-oxide ceramics. Dent Mater. 2009 Mar;25(3):392-9.

11. Sorensen JA, Engelman MJ, Torres TJ, Avera SP. Shear bond strength of composite resin to porcelain. Int J Prosthodont. 1991 Jan-Feb;4(1):17-23.

12. Barghi N. To silanate or not to silanate: making a clinical decision. Compend Contin Educ Dent. 2000 Aug;21(8):659-62, 664; quiz 666

\section{Conclusion}

Within the limitations of the present study, it can be concluded that the presence of glass particles on the ceramic surface, associated with silane coupling, improved the $\mu$ sbs between the resin cement and the zirconia disc. The quantity of glass on the zirconia surface modified the failure mode, increasing the number of cement cohesive failures.

13. Derand T, Molin M, Kvam K. Bond strength of composite luting cement to zirconia ceramic surfaces. Dent Mater. 2005 Dec;21(12):1158-62.

14. Horn HR. Porcelain laminate veneers bonded to etched enamel. Dent Clin North Am. 1983 Oct;27(4):671-84.

15. Soderholm KJ, Shang SW. Molecular orientation of silane at the surface of colloidal silica. J Dent Res. 1993 Jun;72(6):1050-4.

16. Cavalcanti AN, Foxton RM, Watson TF, Oliveira MT, Giannini M, Marchi GM. Bond strength of resin cements to a zirconia ceramic with different surface treatments. Oper Dent. 2009 May-Jun;34(3):280-7.

17. Liu D, Pow EH, Tsoi JK, Matinlinna JP. Evaluation of four surface coating treatments for resin to zirconia bonding. J Mech Behav Biomed Mater. 2014 Apr;32:300-9.

18. Kim BK, Bae HE, Shim JS, Lee KW. The influence of ceramic surface treatments on the tensile bond strength of composite resin to all-ceramic coping materials. J Prosthet Dent. 2005 Oct;94(4):357-62.

19. Senyilmaz DP, Palin WM, Shortall AC, Burke FJ. The effect of surface preparation and luting agent on bond strength to a zirconium-based ceramic. Oper Dent. 2007 Nov-Dec;32(6):623-30.

20. Borges GA, Sophr AM, Goes MF, Correr Sobrinho L, Chan DC. Effect of etching and airborne particle abrasion on the microstructure of different dental ceramics. J Prosthet Dent. 2003 May;89(5):479-88.

21. Kim MJ, Kim YK, Kim KH, Kwon TY. Shear bond strengths of various luting cements to zirconia ceramic: surface chemical aspects. J Dent. 2011 Nov;39(11):795-803.

22. Atsu SS, Kilicarslan MA, Kucukesmen HC, Aka PS. Effect of zirconium-oxide ceramic surface treatments on the bond strength to adhesive resin. J Prosthet Dent. 2006 Jun;95(6):430-6.

23. Menani LR, Farhat IA, Tiossi R, Ribeiro RF, Guastaldi AC. Effect of surface treatment on the bond strength between yttria partially stabilized zirconia ceramics and resin cement. J Prosthet Dent. 2014 Aug;112(2):357-64.

24. Wolfart M, Lehmann F, Wolfart S, Kern M. Durability of the resin bond strength to zirconia ceramic after using different surface conditioning methods. Dent Mater. 2007 Jan;23(1):45-50. 
25. Aboushelib MN. Fusion sputtering for bonding to zirconia-based materials. J Adhes Dent. 2012 Aug;14(4):323-8.

26. Blatz MB, Chiche G, Holst S, Sadan A. Influence of surface treatment and simulated aging on bond strengths of luting agents to zirconia. Quintessence Int. 2007 Oct;38(9):745-53.

27. Kumbuloglu O, Lassila LV, User A, Vallittu PK. Bonding of resin composite luting cements to zirconium oxide by two air-particle abrasion methods. Oper Dent. 2006 Mar-Apr;31(2):248-55.
28. Mak YF, Lai SC, Cheung GS, Chan AW, Tay FR, Pashley DH Micro-tensile bond testing of resin cements to dentin and an indirect resin composite. Dent Mater. 2002 Dec;18(8):609-21.

29. Matinlinna JP, Heikkinen T, Ozcan M, Lassila LV, Vallittu PK. Evaluation of resin adhesion to zirconia ceramic using some organosilanes. Dent Mater. 2006 Sep;22(9):824-31.

30. DeHoff PH, Anusavice KJ, Wang Z. Three-dimensional finite element analysis of the shear bond test. Dent Mater. 1995 Mar;11(2):126-31. 